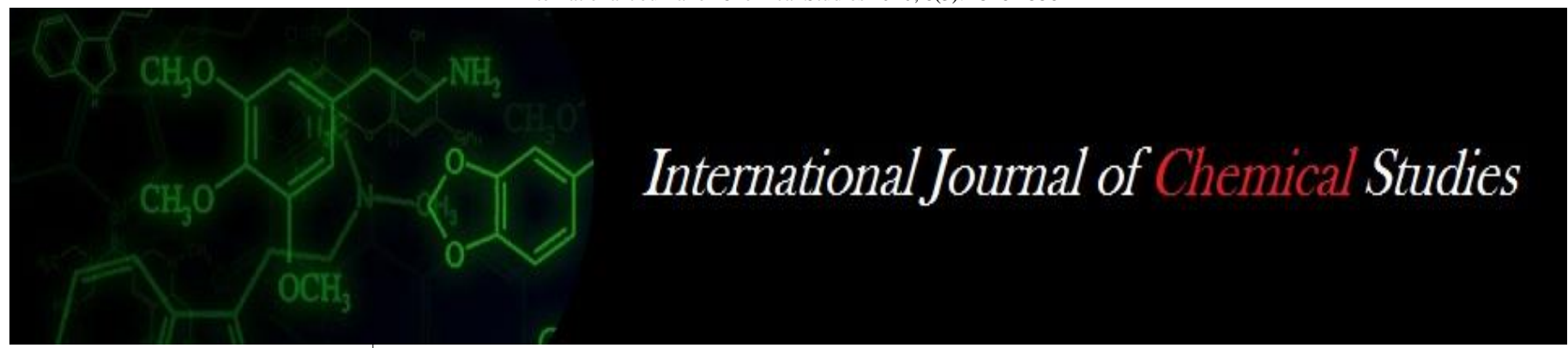

P-ISSN: 2349-8528

E-ISSN: 2321-4902

www.chemijournal.com

IJCS 2020; 8(3): 1548-1558

(C) 2020 IJCS

Received: 16-03-2020

Accepted: 18-04-2020

Baishali Mishra

Department of Mathematics and

Statistics, C.C.S. Haryana

Agricultural University, Hisar,

Haryana, India

Vinod Kumar

Department of Mathematics,

Statistics and Computer Science

G.B.Pant University of

Agriculture and Technology,

Pantnagar, Uttarakhand, India

Corresponding Author: Baishali Mishra

Department of Mathematics and Statistics, C.C.S. Haryana

Agricultural University, Hisar,

Haryana, India

\section{Soil characteristics status in different tehsils of Mirzapur (U.P)}

\section{Baishali Mishra and Vinod Kumar}

DOI: https://doi.org/10.22271/chemi.2020.v8.i3u.9414

\begin{abstract}
Soil plays a major role in determining the sustainable productivity of an agro-ecosystem. Crop production potential is greatly influenced by the soil characteristics such as $\mathrm{pH}$, Electrical Conductivity (EC), Organic Carbon (OC), Nitrogen, Phosphorus and other nutrients. These characteristics are related to soil fertility and agricultural productivity of a particular place. The present study was conducted to statistically analyze the soil characteristics data of Mirzapur district. Distribution pattern of all soil characteristics are examined and Goodness of fit of the best fitted distributions is tested by Chi-Square test. $\mathrm{pH}, \mathrm{EC}, \mathrm{OC}$ and Boron are found to follow Dagum distribution whereas Potassium and Iron are found to follow Fatigue Life distribution. Moreover EC, Nitrogen, Phosphorus, Sulphur, Maganese and Zinc are found to follow General Extreme Value, Error, Pearson 5, Pearson 5 (3P), Pearson 6 and Inverse Gaussian (3P) distributions respectively. Descriptive measures (Mean, Standard deviation, Skewness and Kutosis) are also calculated to know the soil status of Mirzapur district.
\end{abstract}

Keywords: Electrical conductivity, organic carbon, best fit, skewness, kurtosis

\section{Introduction}

Soil is the loose collection of fragmented and chemically weathered rock mixed with organic and living matter on the earth's surface capable of sustaining plants. Soil consists of a solid phase of minerals and organic matter, as well as a porous phase that holds gases (the soil atmosphere) and water (the soil solution). Consequently, soils are often treated as a three-state system of solids, liquids and gases. Soil is a product of

the influence of climate, relief (elevation, orientation and slope of terrain), organisms and its parent materials (original minerals) interacting over time. Since soil has a great variety of available organisms and habitats, it comprises most of the Earth's genetic diversity. Soil characteristics and properties are determining factors for the growth of plants. Determining the characteristics of soils will eventually help to determine how to manage them effectively. The availability of nutrients is particularly sensitive to changes in soil environment. The factors that affect the contents of nutrients are organic matter, soil $\mathrm{pH}$ and electrical conductivity. The study is based on the soil characteristics data related to the farmers of sampled villages of different blocks of Mirzapur district of Uttar Pradesh. The probability distributions followed by different soil characteristics are investigated in this research paper.

\section{Materials and methods}

\section{1. Description of the study area}

The study area for the present work is Mirzapur district of Uttar Pradesh (UP) which is situated between latitude $23.52^{\circ}$ to $23.32^{\circ}$ and longitude $82.72^{\circ}$ to $83.33^{\circ}$. It covers an area of 4521 sq. $\mathrm{km}$. Total population of the district is more than 20 lacs. Mirzapur is divided into 4 thesils, 12 blocks and 973 gram sabhas consisting of 1698 villages.

The region has limited water resources and the land is mostly degraded. It has only $40 \%$ cultivable land with no assured irrigation facility. Therefore, farmers have to face a lot of challenges while growing crops to these dry lands in the absence of rain and irrigation system. The soil is generally red and the terrain is generally rocky in the district. The district has 4, 50,169 hectares geographical area. The study is confined to four tehsils of Mirzapur district namely Mirzapur (Sadar), Marihan, Lalganj and Chunar, having 12 blocks namely Sikhar, 
Narayanpur, Jamalpur, Kon, Majhwa, Nagar, Rajgarh, Chinnoway, Marhian, Lalganj, Halia and Pahari.

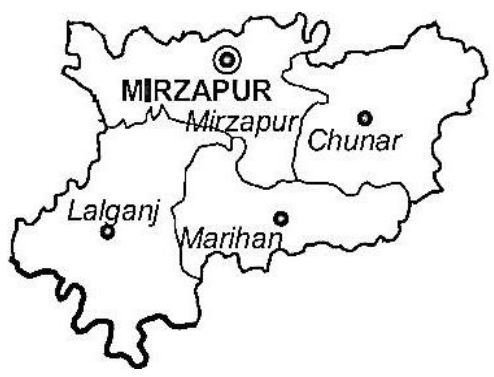

Fig 2.1: Map of Mirzapur district

\subsection{Source of the data}

The present study mainly hinges on secondary data on some important soil characteristics viz. pH, Electrical Conductivity (EC), Organic Carbon (OC), Nitrogen, Phosphorus, Carbon, Potassium, Zinc, Boron, Iron, Magnesium and Sulphur obtained from the "Regional Soil Testing Laboratory, Varanasi, Government of Uttar Pradesh and AICRP (All India Coordinated Research Projects), Varanasi Centre sponsored by Ministry of Agriculture, Government of India". Soil data obtained are related to the farmers of sampled villages of twelve blocks under four tehsils in Mirzapur district.

\subsection{Statistical techniques used \\ 2.3.1 Best fit distribution}

Best fit distribution is the fitting of a probability distribution to a series of data concerning the repeated measurement of a particular variable. Distribution fitting helps in developing valid models for random processes, protects from potential time and money loss which can arise due to invalid model selection and results in better decisions.

Easy Fit Professional 5.6 was used to find best fitted distribution on several soil characteristics of the Mirzapur district. This software fits a number of distributions for the given data and then decides the best amongst them on the basis of Chi Square, Kolmogrov-Smirnov and AndersonDarling tests. Further, the parameters of the best fitted distribution may be estimated by using any classical method of estimation e.g. Method of Moments, Method of Maximum Likelihood etc.

\subsubsection{Method of moments}

Method of Moments is a method of estimating population parameters, given by Karl Pearson. This method consists of equating the sample moments to the corresponding moments of population, which are the functions of unknown parameters. We equate as many sample moments as there are unknown parameters and solve the simultaneous equations for estimating unknown parameters. This results in estimates of unknown parameters.

\subsubsection{Descriptive statistics}

Descriptive statistics are used to describe the basic features of the data in a study. They provide simple summaries about the sample and the measures. The Descriptive statistics such as the Mean, Standard Deviation, Coefficients of Skewness and Kurtosis may be used to study the status of the soil characteristics in Mirzapur district. The standard formulae are used to compute the above said measures. Coefficients of Skewness and Kurtosis, denoted respectively by $\gamma_{1}$ and $\gamma_{2}$ are defined by

$$
\begin{aligned}
& \gamma_{1}=\frac{n}{(n-1)(n-2)} \sum_{i=1}^{n}\left(\frac{x_{i}-\bar{x}}{s}\right)^{3} \\
& \gamma_{2}=\left[\frac{n(n+1)}{(n-1)(n-2)(n-3)} \sum_{i=1}^{n}\left(\frac{x_{i}-\bar{x}}{s}\right)^{4}\right]-\frac{3(n-1)^{2}}{(n-2)(n-3)}
\end{aligned}
$$

The above said formulae have been used for the purpose of calculation of Coefficients of Skewness and Kurtosis in MSExcel software through which calculations have to be done.

\section{Results and discussion}

\subsection{Best fitted distributions of soil characteristics}

The soil characteristics (pH, EC, OC, N, P, K, S, Fe, Mn, Cu, $\mathrm{Zn}$ and $\mathrm{B}$ ) were analyzed for their best fitted distribution. Here we have considered rank of Chi-Square test to determine best fit distribution. Distribution patterns of different soil characteristics are presented in Table 3.1.

On the basis of ranks assigned to Chi-Square statistic for various distributions, Dagum distribution is found to be the best fit distribution for soil $\mathrm{pH}, \mathrm{OC}$, Copper and Boron as shown in Table 3.1. Similarly Fatigue Life distribution is the best fit distribution for Potassium and Iron. Gen Extreme Value distribution for EC and Error distribution for Nitrogen are the best fit distributions. Moreover, Sulphur follows Pearson 5 (3P) while Phosphorus follows Pearson 5 distribution. Pearson 6 is the best fit distribution for Manganese and Inv. Gaussian (3P) is best fit distribution for Zinc. The probability curves for the best fit distributions of the above said characteristics have also been plotted and are given in Figures 3.1 to 3.12 .

Table 3.1: Best fit distributions of different soil characteristics

\begin{tabular}{|c|c|c|c|}
\hline S. No. & Soil characteristics & Best fit distribution & Parameters \\
\hline 1 & $\mathrm{pH}$ & Dagum & $\mathrm{k}=0.21377, \mathrm{a}=39.71, \mathrm{~b}=8.3645$ \\
\hline 2 & $\mathrm{EC}$ & Gen. Extreme Value & $\mathrm{k}=0.35011, \mathrm{~s}=0.03449, \mathrm{~m}=0.05387$ \\
\hline 3 & OC & Dagum & $\mathrm{k}=0.44264, \mathrm{a}=6.2611, \mathrm{~b}=0.66418$ \\
\hline 4 & Nitrogen & Error & $\mathrm{k}=1.5564, \mathrm{~s}=30.385, \mathrm{~m}=126.61$ \\
\hline 5 & Phosphorus & Pearson 5 & $\mathrm{a}=2.0102, \mathrm{~b}=34.974$ \\
\hline 6 & Potassium & Pearson 5 (3P) & $\mathrm{a}=59828, \mathrm{~b}=212.76$ \\
\hline 7 & Sulphur & Fatigue Life & $\mathrm{a}=1.4375, \mathrm{~b}=18.288$ \\
\hline 8 & Iron & Dagum & $\mathrm{k}=0.23193, \mathrm{a}=6.031, \mathrm{~b}=2.2811$ \\
\hline 9 & Copper & Pearson 6 & $\mathrm{a}=2.5063, \mathrm{a}=3.0673, \mathrm{~b}=9.6582$ \\
\hline 10 & Maganese & Inv. Gaussian $(3 \mathrm{P})$ & $\mathrm{l}=3.4516, \mathrm{~m}=1.5666, \mathrm{~g}=-0.23878$ \\
\hline 11 & Zinc & Dagum & $\mathrm{k}=0.76717, \mathrm{a}=3.4128, \mathrm{~b}=0.47889$ \\
\hline 12 & Boron & &
\end{tabular}




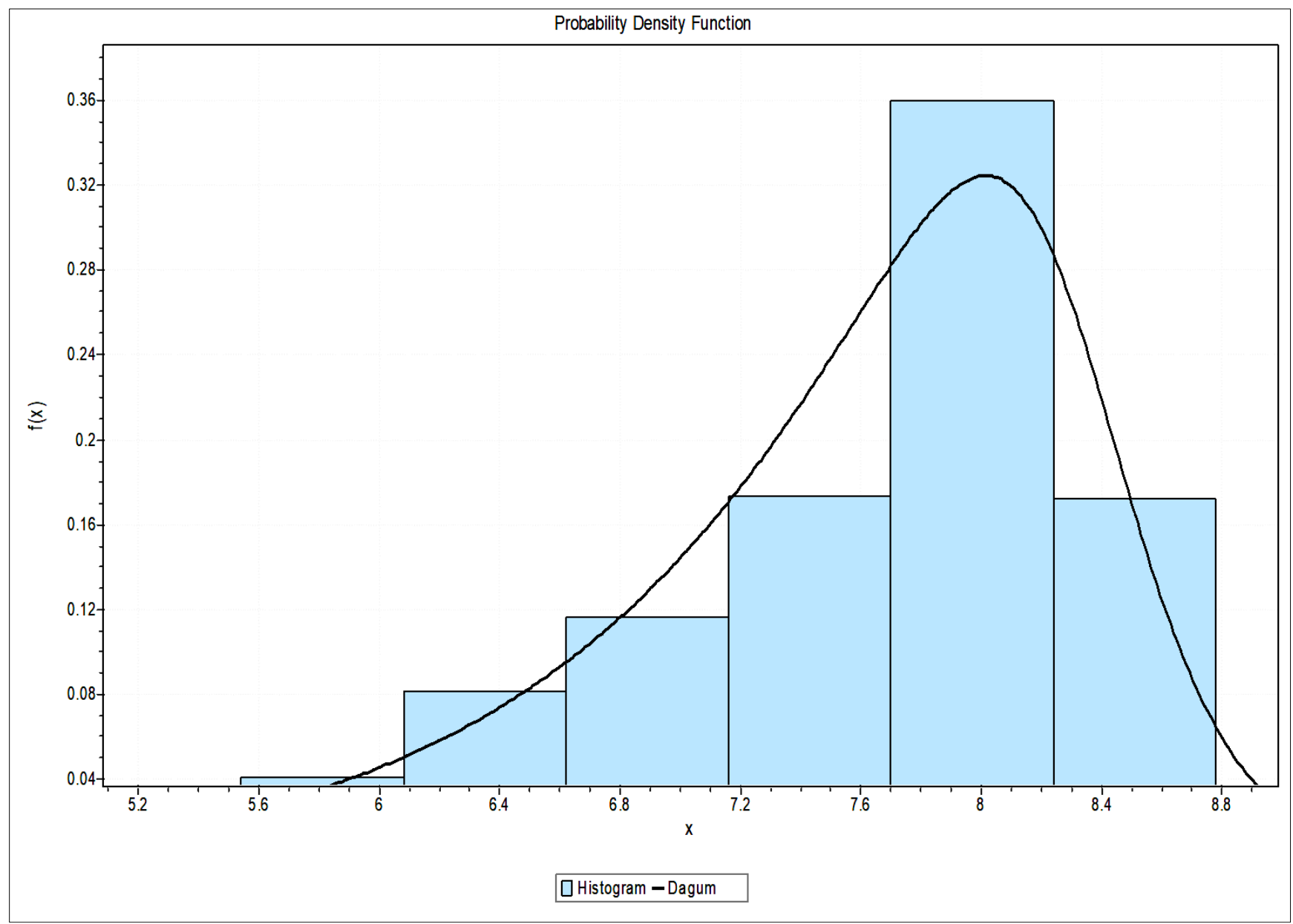

Fig 3.1: Probability curve of best fitted distribution of $\mathrm{pH}$

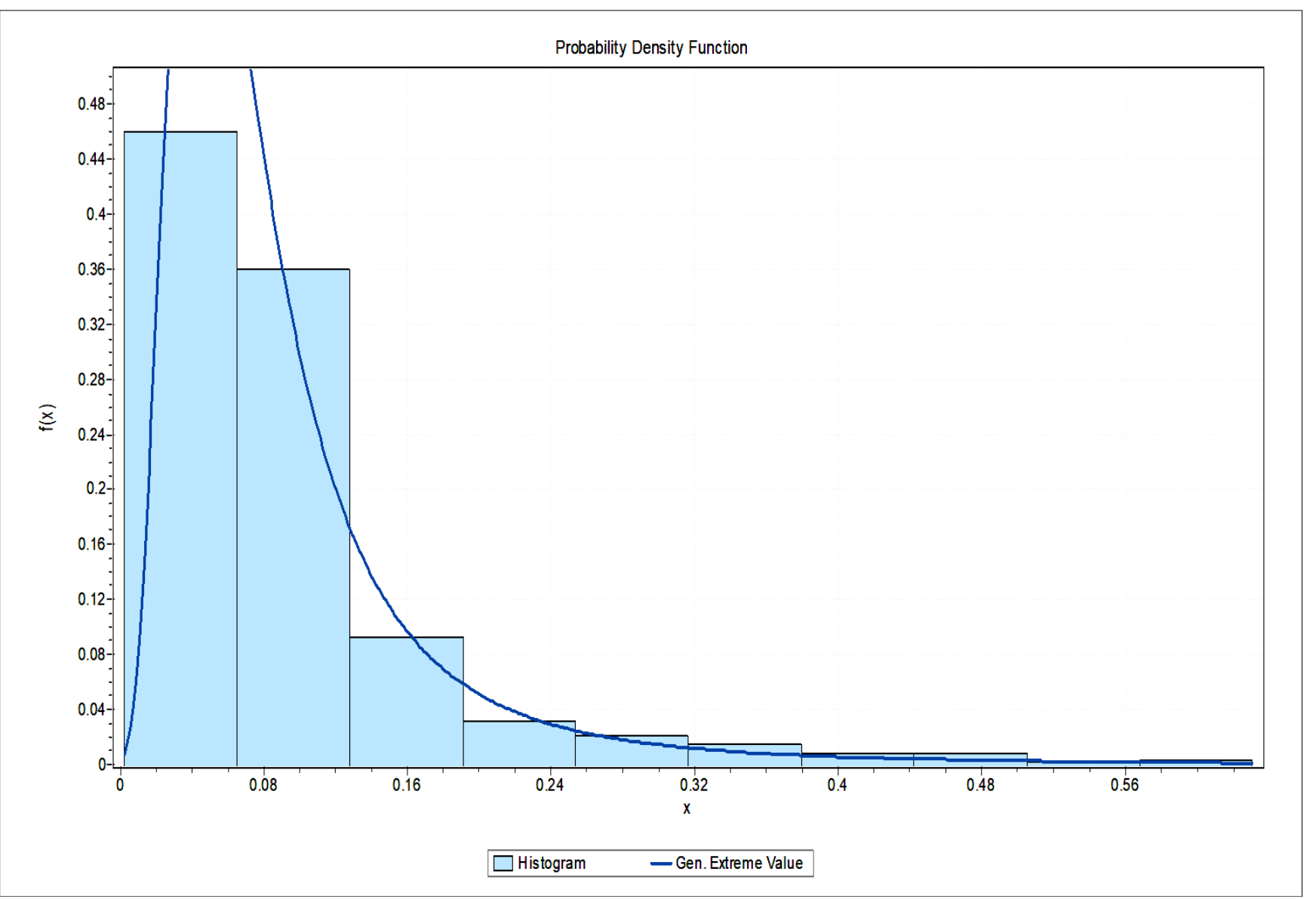

Fig 3.2: Probability curve of best fitted distribution of EC 


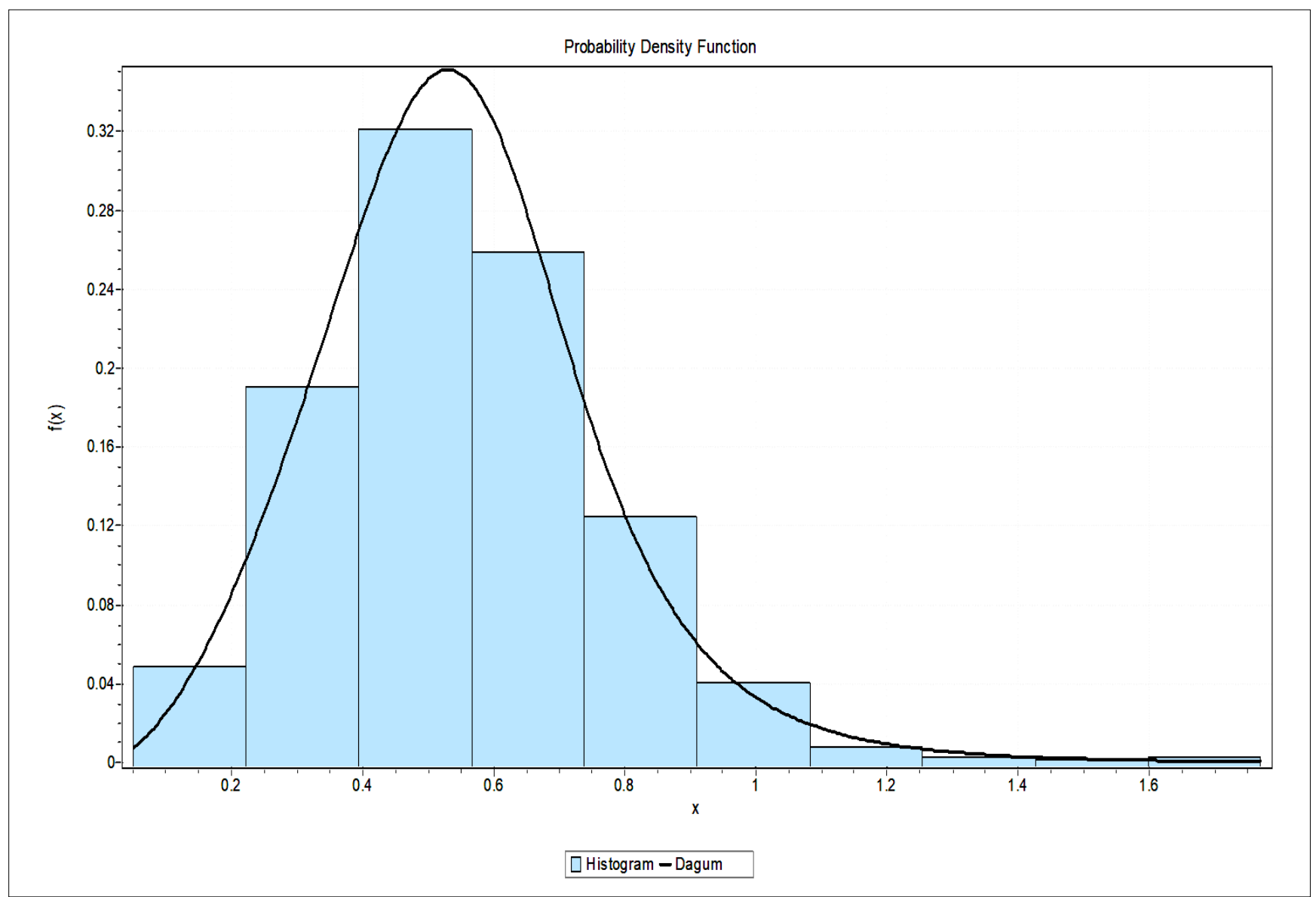

Fig 3.3: Probability curve of best fitted distribution of OC

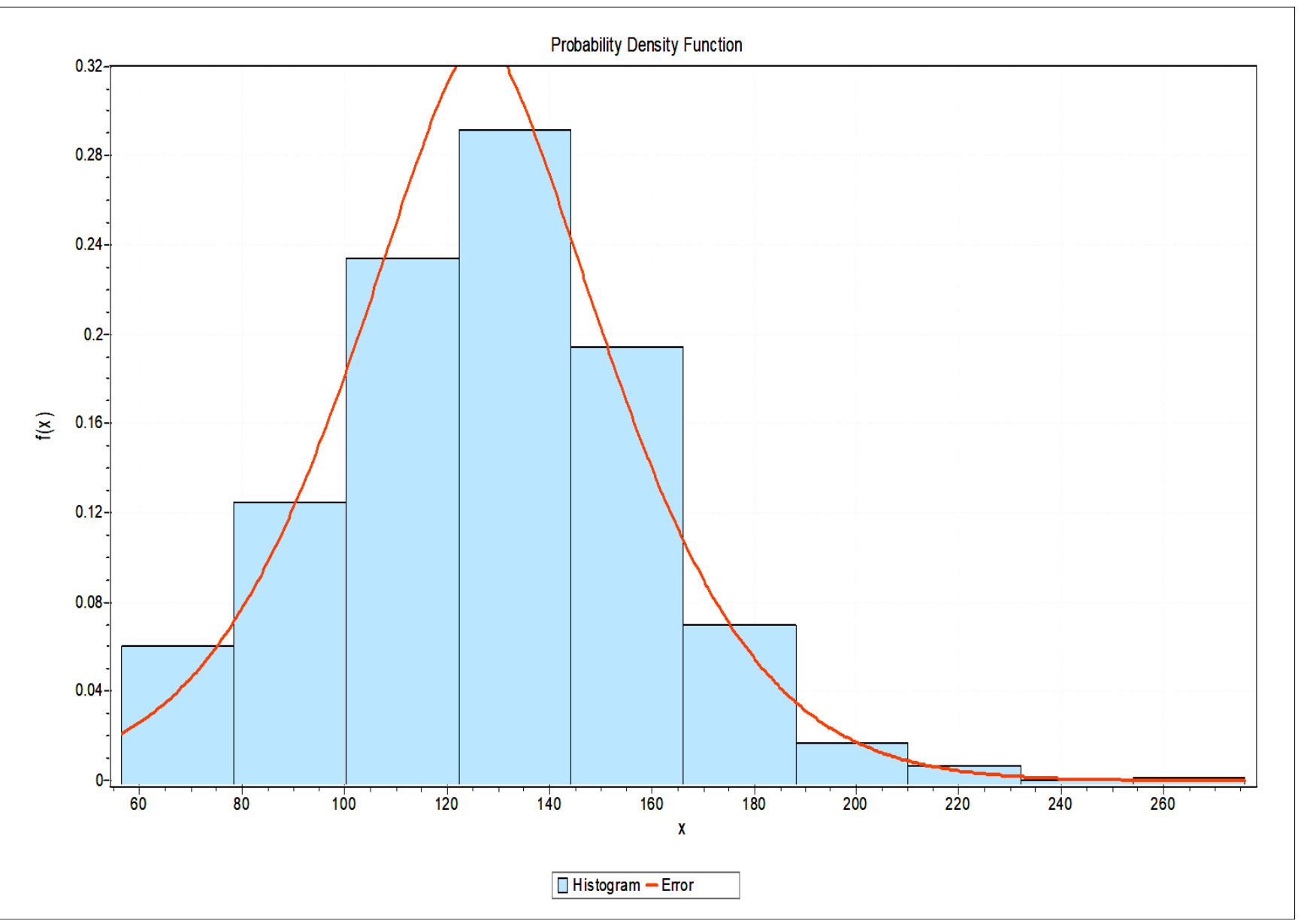

Fig 3.4: Probability curve of best fitted distribution of Nitrogen 


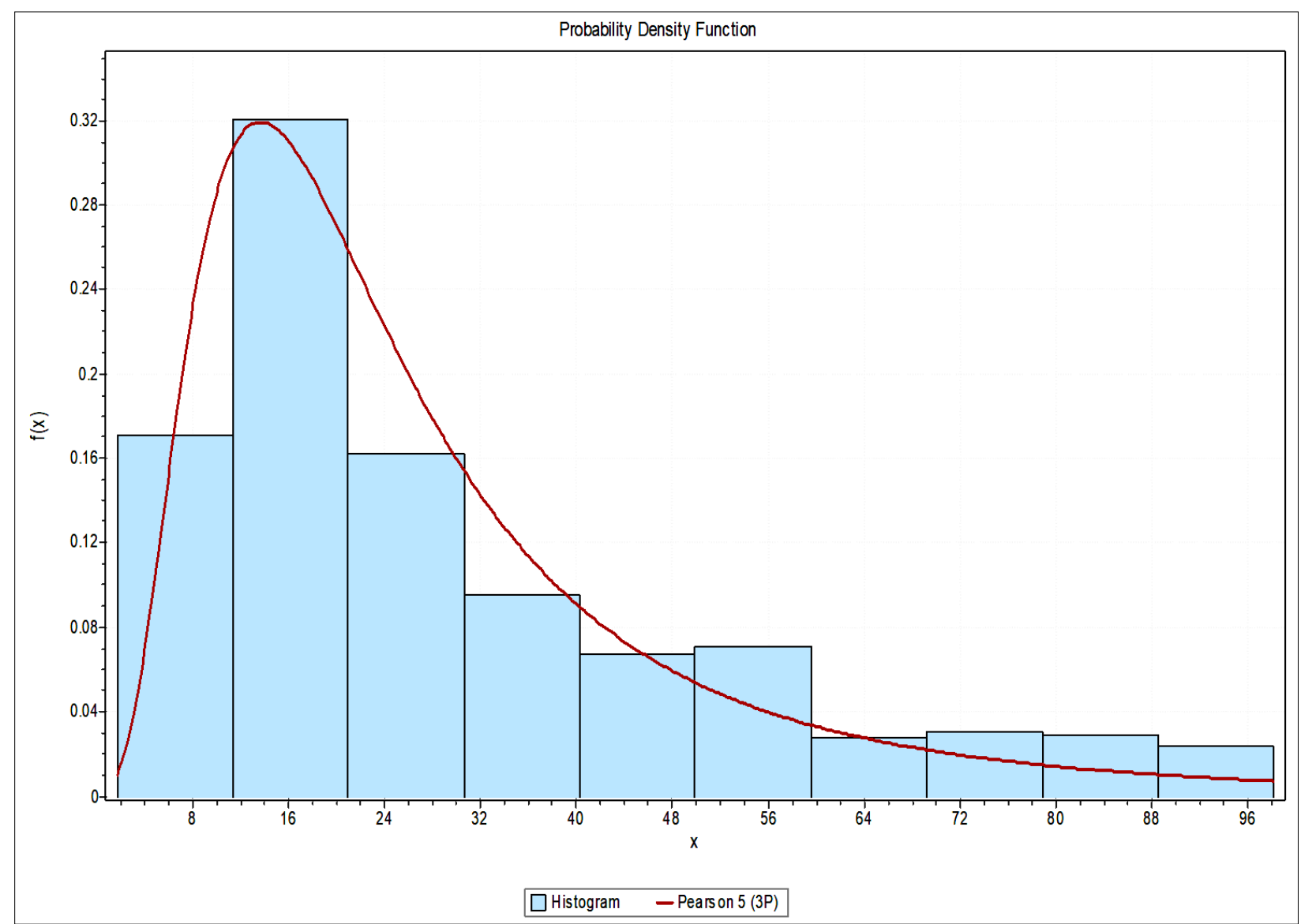

Fig 3.5: Probability curve of best fitted distribution of Phosphorus

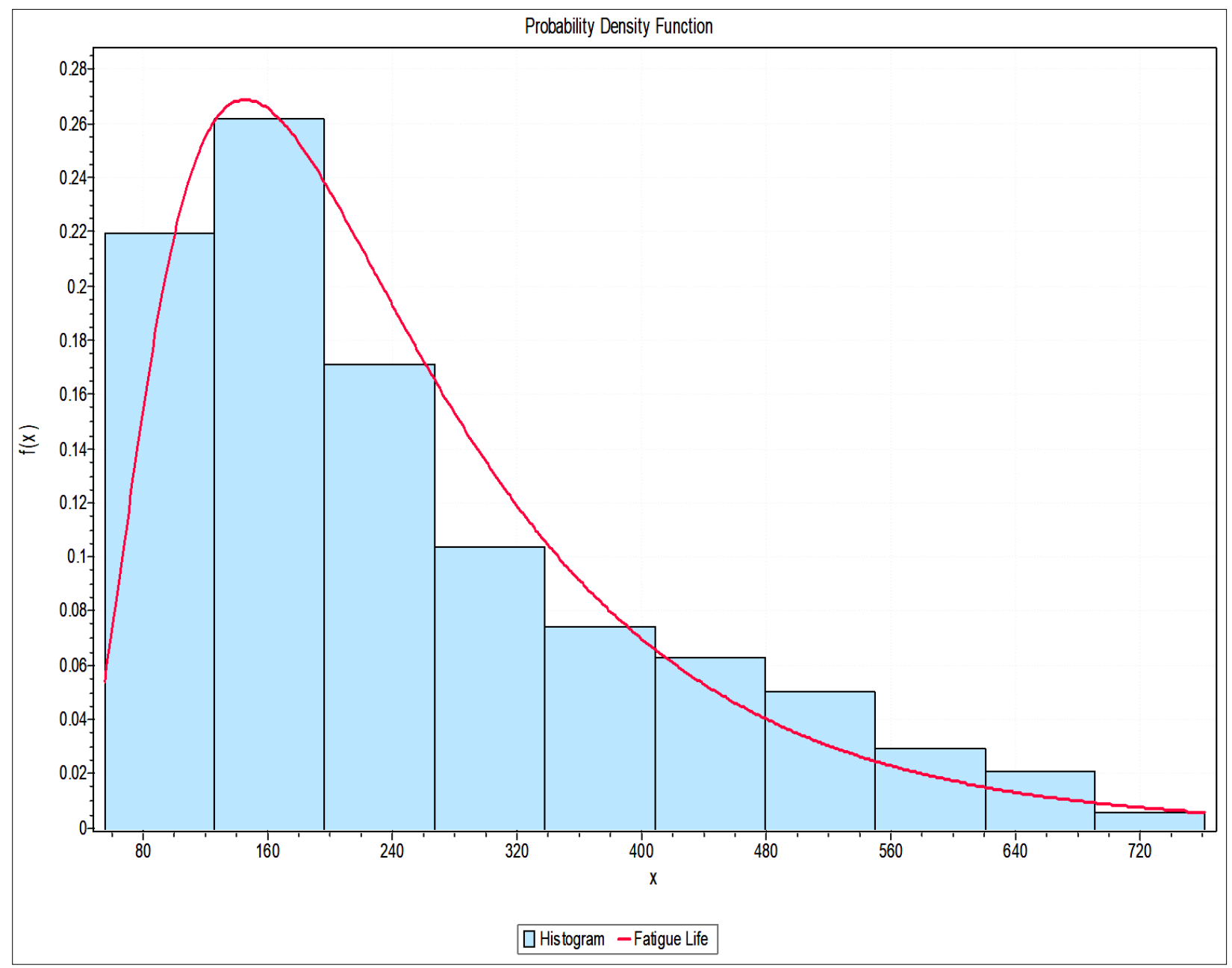

Fig 3.6: Probability curve of best fitted distribution of Potassium 


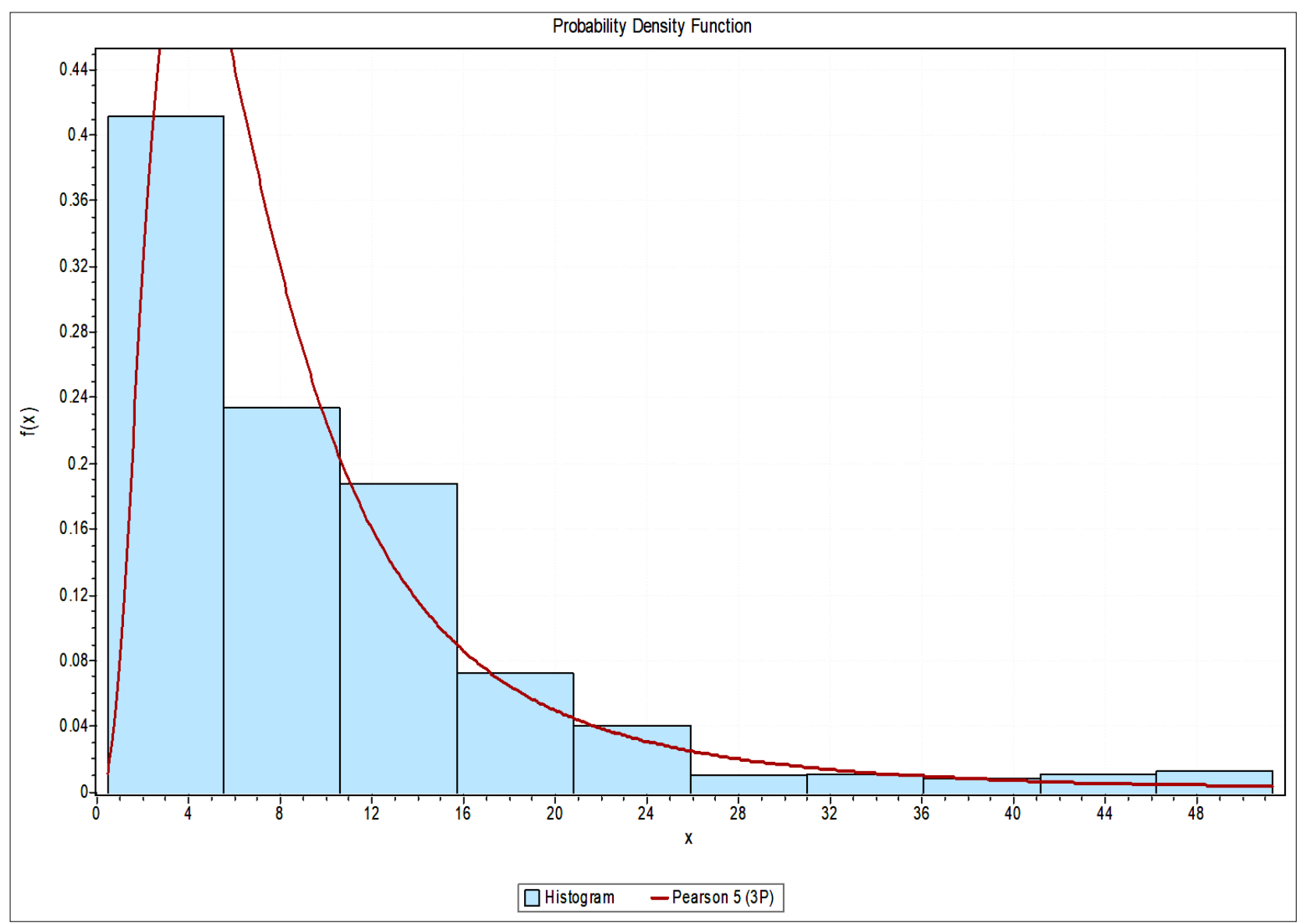

Fig 3.7: Probability curve of best fitted distribution of Sulphur

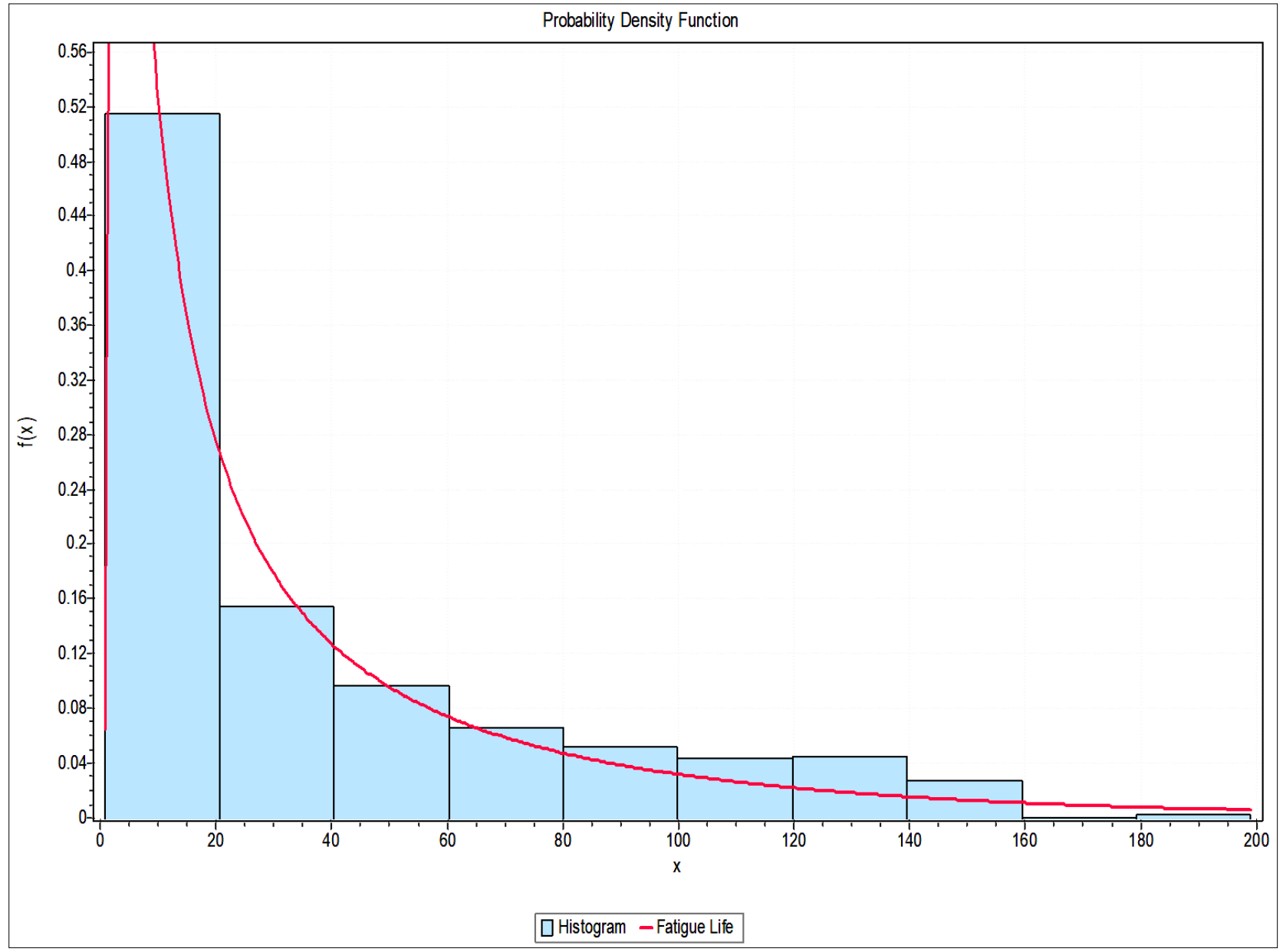

Fig 3.8: Probability curve of best fitted distribution of Iron 


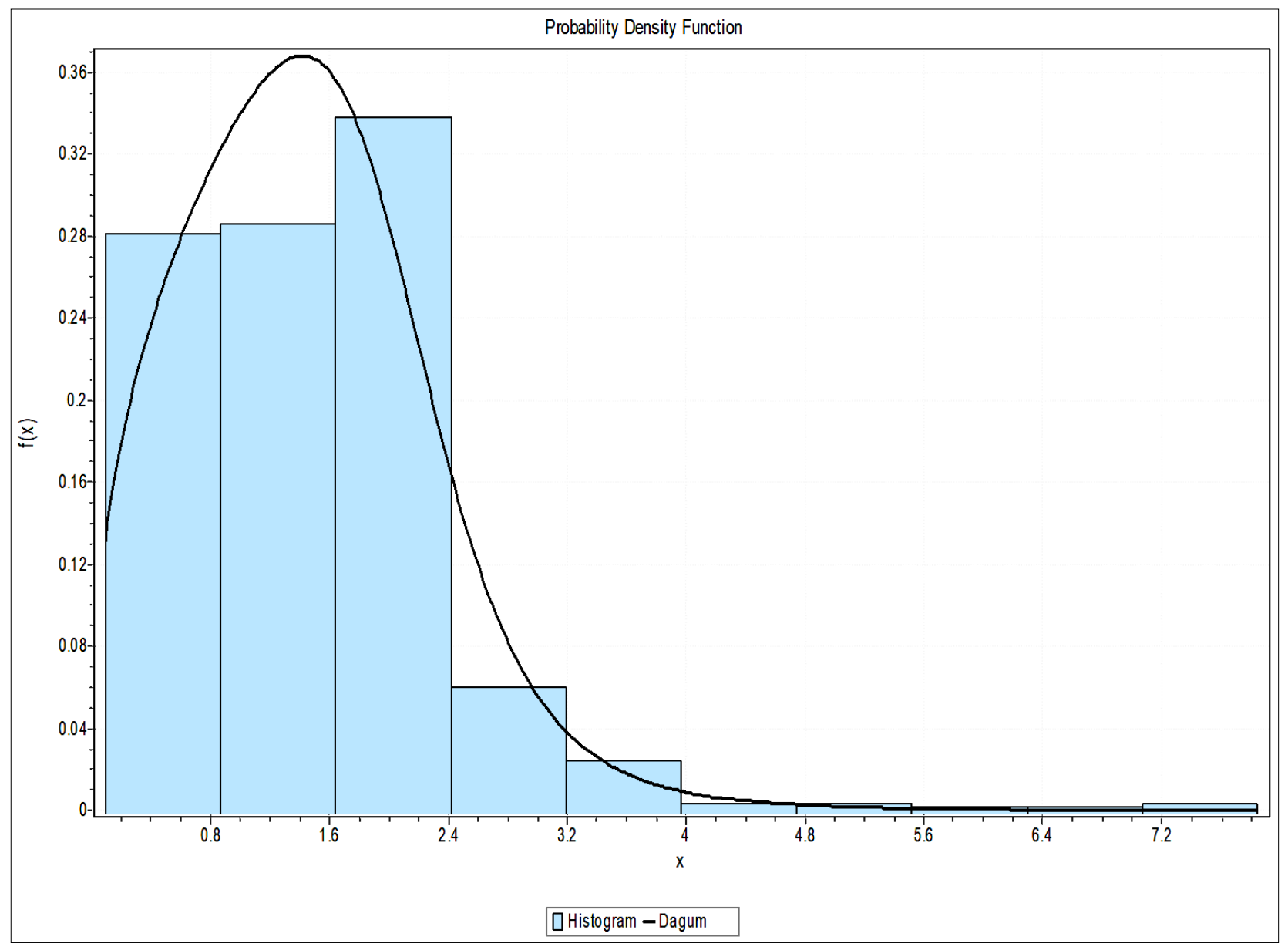

Fig 3.9: Probability curve of best fitted distribution of Copper

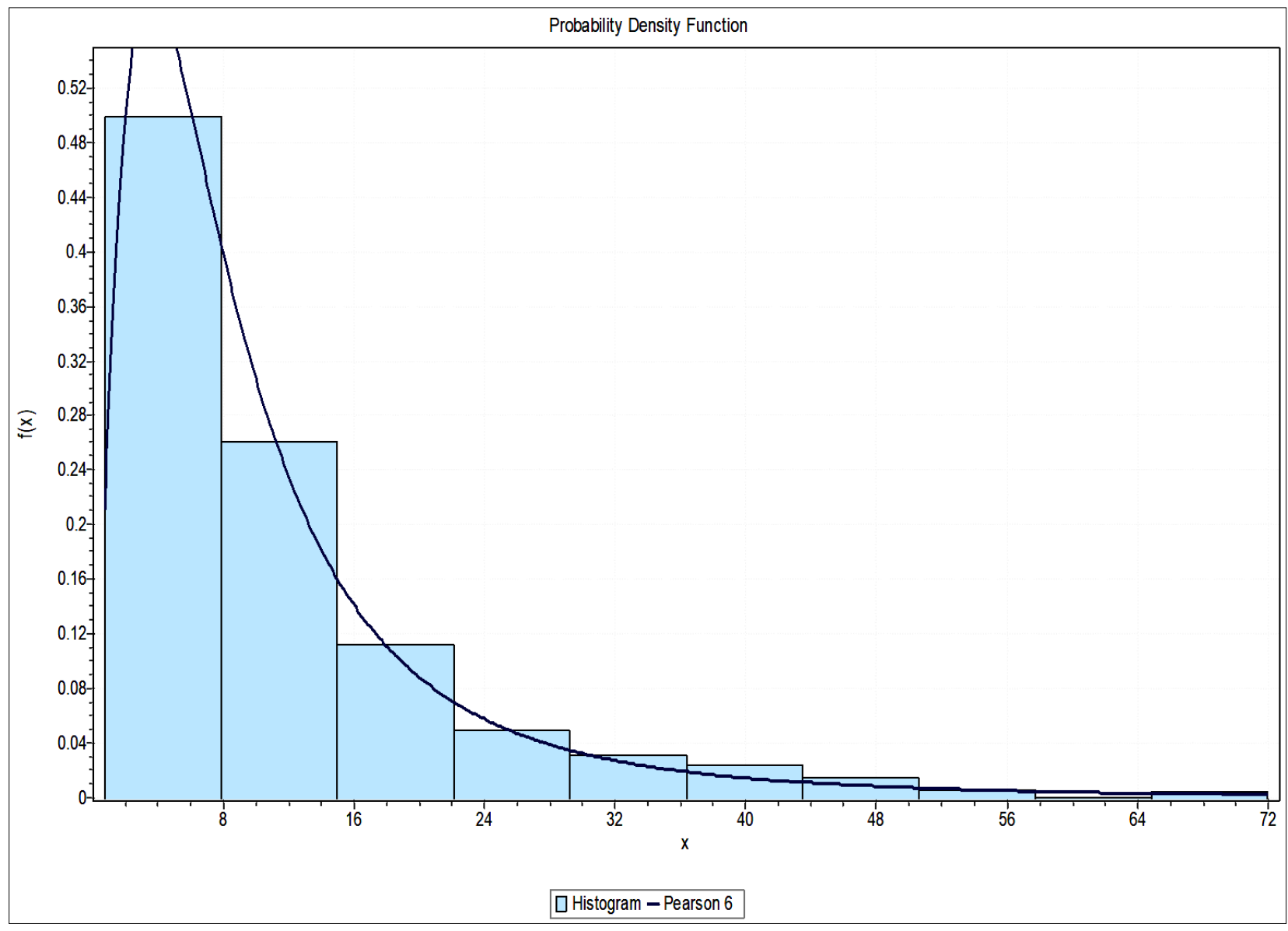

Fig 3.10: Probability curve of best fitted distribution of Maganese 


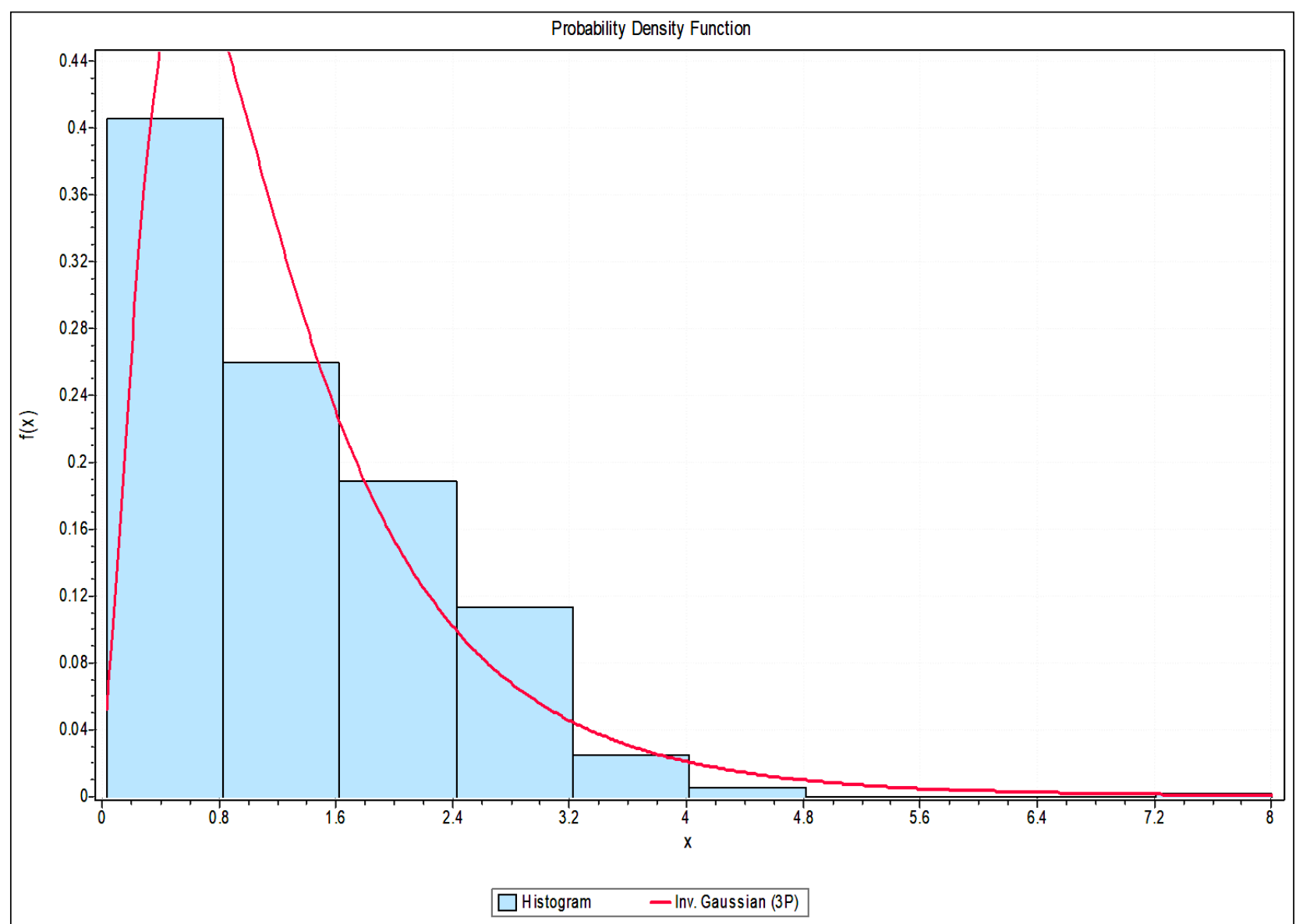

Fig 3.11: Probability curve of best fitted distribution of Zinc

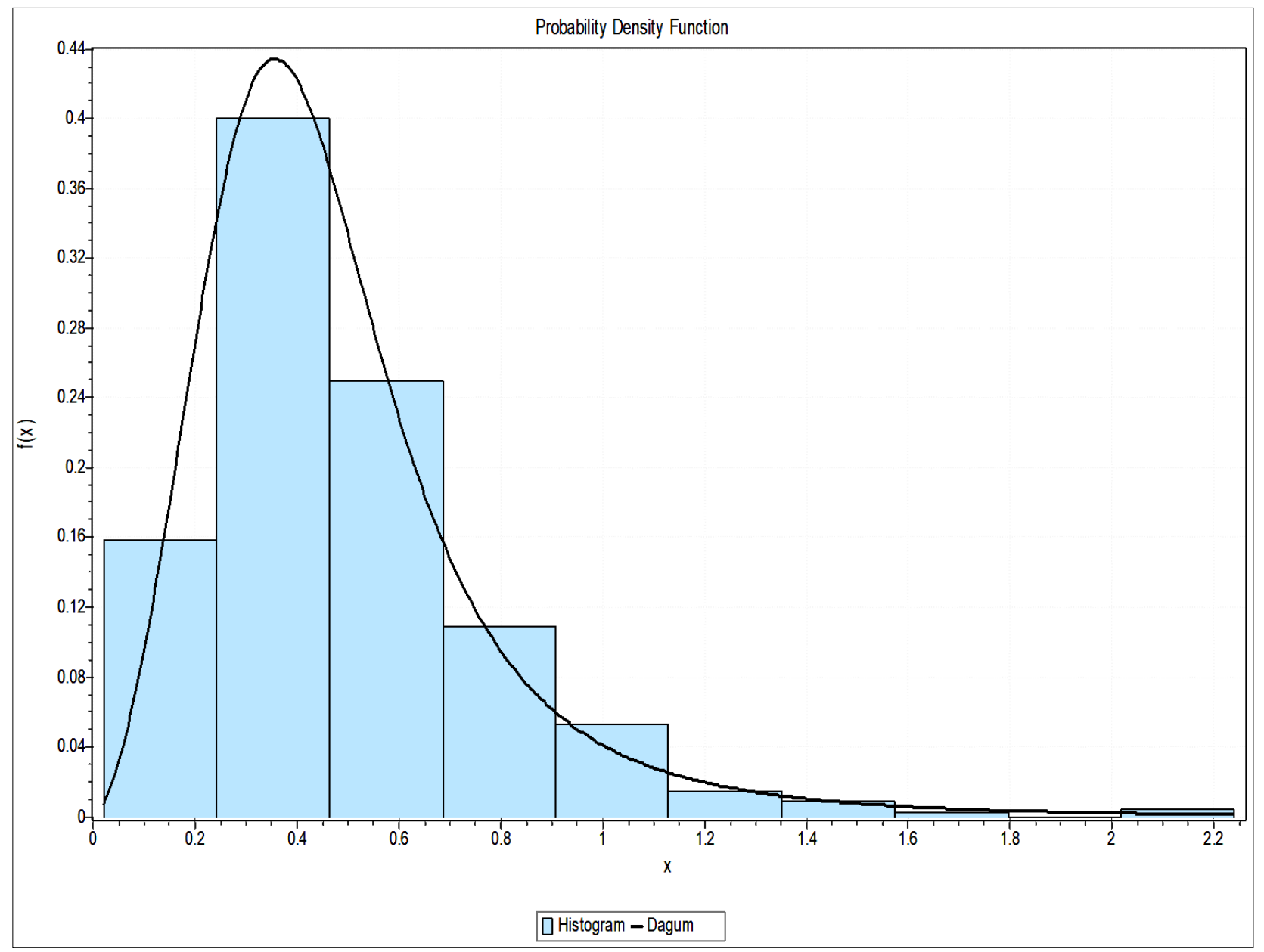

Fig 3.12: Probability curve of best fitted distribution of Boron 
A continuous random variable $X$ is said to have a threeparameter Dagum distribution, abbreviated as $\mathrm{X} \sim \operatorname{Dag}(\beta, \lambda, \delta)$ if its probability density function is given as

$F(x ; \beta, \lambda, \delta)=\beta \lambda \delta x^{-\delta-1}\left(1+\lambda x^{-\delta}\right)^{-\beta-1}, 0<x<\infty$

Where $\lambda>0$ is the scale parameter and its two shape parameters $\beta$ and $\delta$ are both positive.

Three parameters of Dagum distribution can be estimated with the help of method of moments.

$\mathbf{r}^{\text {th }}$ moment of $X$

$$
\mu^{\prime}{ }_{r}^{\prime}=\int_{0}^{\infty} x^{r} \beta \lambda \delta x^{-\delta-1}\left(1+\lambda x^{-\delta}\right)^{-\beta-1} d x
$$

Letting $\lambda x^{-\delta}=y$ we get

$$
\begin{aligned}
& -\lambda \delta x^{-\delta-1} d x=d y \text { and } x=\left(\frac{y}{\lambda}\right)^{\frac{-1}{\delta}} \\
& \boldsymbol{\mu}_{\mathrm{r}}^{\mathrm{r}}=\beta \lambda \delta_{\infty}^{0} \frac{\left(\frac{y}{\lambda}\right)^{\frac{-r}{\delta}}}{(1+y)^{\beta+1}} \frac{d y}{-\lambda \delta}
\end{aligned}
$$

$$
\begin{aligned}
& \boldsymbol{\mu}_{\mathrm{r}=}=\lambda^{\frac{\beta}{\frac{-r}{\delta}}} \int_{0}^{\infty} \frac{y^{\frac{-r}{\delta}+1-1}}{(1+y)^{1-\frac{r}{\delta}+\beta+\frac{r}{\delta}}} d y \\
& \boldsymbol{\mu}_{\mathrm{r}}^{\prime}=\lambda^{\frac{\beta}{\frac{-r}{\delta}} \mathrm{B}\left(1-\frac{r}{\delta}, \beta+\frac{r}{\delta}\right)} \\
& \boldsymbol{\mu}^{\prime}{ }_{1}=
\end{aligned}
$$

First raw moment

$$
\boldsymbol{\mu}_{\mathbf{1}}^{\prime}=\beta \lambda^{\frac{1}{\delta}} \mathrm{B}\left(1-\frac{1}{\delta}, \beta+\frac{1}{\delta}\right)=\mathbf{m}_{\mathbf{1}}
$$

Second raw moment

$$
\boldsymbol{\mu}_{2}^{\prime}=\beta \lambda^{\frac{2}{\delta}} \mathrm{B}\left(1-\frac{2}{\delta}, \beta+\frac{2}{\delta}\right)=\mathbf{m}_{\mathbf{2}}
$$

Third raw moment

$$
\begin{aligned}
& \boldsymbol{\mu}^{\prime}{ }_{3}=\beta \lambda^{\frac{3}{\delta}} \mathrm{B}\left(1-\frac{3}{\delta}, \beta+\frac{3}{\delta}\right)=\mathbf{m}^{\prime}{ }_{3} \\
& \frac{m_{2}^{\prime}}{m_{1}^{\prime}}=\frac{{ }^{\frac{1}{\delta}}}{\mathrm{B}\left(1-\frac{2}{\delta}, \beta+\frac{2}{\delta}\right)}
\end{aligned}
$$

$$
\begin{aligned}
& \frac{m_{2}^{\prime}}{m_{1}^{\prime}}=\frac{\lambda^{\frac{1}{\delta}} \frac{\Gamma\left(1-\frac{2}{\delta}\right) \Gamma\left(\beta+\frac{2}{\delta}\right)}{\Gamma\left(1-\frac{1}{\delta}\right) \Gamma\left(\beta+\frac{1}{\delta}\right)}}{\frac{m_{3}^{\prime}}{m_{2}^{\prime}}=\lambda^{\frac{1}{\delta}} \frac{\Gamma\left(1-\frac{3}{\delta}\right) \Gamma\left(\beta+\frac{3}{\delta}\right)}{\Gamma\left(1-\frac{2}{\delta}\right) \Gamma\left(\beta+\frac{2}{\delta}\right)}} \\
& \frac{m_{2}^{\prime}}{m_{1}^{\prime}} \times \frac{m_{2}^{\prime}}{m_{3}^{\prime}}=\frac{\left[\Gamma\left(1-\frac{2}{\delta}\right) \Gamma\left(\beta+\frac{2}{\delta}\right)\right]\left[\Gamma\left(1-\frac{2}{\delta}\right) \Gamma\left(\beta+\frac{2}{\delta}\right)\right]}{\left[\Gamma\left(1-\frac{1}{\delta}\right) \Gamma\left(\beta+\frac{1}{\delta}\right)\right]\left[\Gamma\left(1-\frac{3}{\delta}\right) \Gamma\left(\beta+\frac{3}{\delta}\right)\right]}
\end{aligned}
$$

The values of $m_{1}^{\prime}, m_{2}^{\prime}$ and $m_{3}^{\prime}$ may be calculated from the data used for best fit and the parameters of Dagum distribution can be estimated by solving the above said equations by using a suitable numerical method. Similarly the parameters of other distributions can be estimated.

\subsection{Descriptive statistics to examine soil status of Mirzapur}

The descriptive statistics such as Mean, Standard Deviation and Skewness were used to know the variability in the soil characteristics of four tehsils viz., Chunar, Mirzapur, Marhihan and Lalganj of Mirzapur district, Uttar Pradesh and are presented in Table 3.2 to $3.4 \mathrm{~b}$.

\section{Soil properties}

The data presented in Table 3.2 indicate the tehsil wise descriptive statistics of soil properties ( $\mathrm{pH}, \mathrm{EC}$ and OC) of Mirzapur district. It is evident from the findings that the highest average $\mathrm{pH}$ (7.67) was observed in Chunar as compared to lowest average (6.74) in Marhihan. The highest average (0.11) Electrical Conductivity (EC) was found in Chunar Tehsil and lowest EC (0.06) in Marihan Tehsil. Similary, highest average (0.69) OC was observed in Marihan Tehsil as compared to lowest average $(0.51 \%)$. in Mirzapur Tehsil. The Standard deviation (SD) in the soil $\mathrm{pH}$ was found to be highest (1.15) in Lalganj and lowest (0.57) in Mirzapur whereas highest Standard deviation (0.11) of EC was found in Chunar as compared to lowest (0.06) in Marhihan and the Standard deviation of OC was highest $(0.23)$ in Chunar and Lalganj and lowest (0.19) in Mirzapur. Also, the distribution of EC and OC was observed to be positively skewed and leptokurtic in all the four tehsils of Mirzapur district. The distribution of $\mathrm{pH}$ was found to be negatively skewed in all the four tehsils whereas it was leptokurtic in Chunar and Mirzapur tehsils and platykurtic in Lalganj and Marhihan tehsils. 
Table 3.2: Descriptive statistics of soil properties (pH, EC and OC) of Mirzapur tehsils

\begin{tabular}{|c|c|c|c|c|c|c|c|c|c|c|c|c|}
\hline \multirow{2}{*}{ Tehsils } & \multicolumn{4}{|c|}{ pH } & \multicolumn{4}{|c|}{ EC } & \multicolumn{4}{|c|}{$\mathbf{O C}$} \\
\hline & Mean & SD & $\gamma_{1}$ & $\gamma_{2}$ & Mean & SD & $\gamma_{1}$ & $\gamma_{2}$ & Mean & SD & $\gamma_{1}$ & $\gamma_{2}$ \\
\hline Chunar & 7.67 & 0.69 & -0.26 & 0.45 & 0.11 & 0.11 & 2.04 & 4.27 & 0.55 & 0.23 & 0.74 & 2.44 \\
\hline Mirzapur & 7.89 & 0.57 & -0.27 & 2.19 & 0.07 & 0.07 & 4.28 & 24.85 & 0.51 & 0.19 & 0.59 & 0.94 \\
\hline Marihan & 6.74 & 0.81 & -0.03 & -0.92 & 0.06 & 0.06 & 2.74 & 11.37 & 0.69 & 0.22 & 1.13 & 2.32 \\
\hline Lalganj & 7.27 & 1.15 & -0.45 & -0.82 & 0.09 & 0.08 & 2.82 & 11.30 & 0.53 & 0.23 & 1.08 & 3.45 \\
\hline
\end{tabular}

\section{Macronutrients}

Results pertaining to Nitrogen, Phoshphorus and Potassium content of soils of all the four tehsils of Mirzapur district are presented in Table 3.3.

It is evident from the table that the highest average (142.47) Nitrogen was found in Marihan as compared to lowest average (119.03) in Mirzapur. The highest average (33.57) Phosphorus was found in Chunar as compared to lowest average (24.08) in Lalganj and highest average (285.01) Potassium was found in Lalganj while lowest average (219.92) in Mirzapur. The Standard deviation of Nitrogen is found highest (83.13) in Mirzapur as compared to lowest (27.52) in Marhihan.
Phosphorus has highest (23.25) Standard deviation in Chunar while lowest (18.94) in Marhihan. Standard Deviation of Potassium is found to be highest (158.34) in Chunar and lowest (142.41) in Mirzapur. Also, the distribution of Phosphorous and Potassium is found to be positively skewed in all the four tehsils while distribution of Nitrogen was positively skewed in all tehsils except Chunar where it is negatively skewed. Moreover, the distribution of Nitrogen is found to be leptokurtic in Marhihan and Lalganj tehsils and platykurtic in Chunar and Mirzapur tehsils. Distribution of Phosphorus is found to be leptokurtic in all tehsils and the distribution of Potassium is leptokurtic in Chunar and Mirzapur tehsils while platykurtic in Marhihan and Lalganj tehsils.

Table 3.3: Descriptive statistics of soil nutrients Nitrogen $(N)$, Phosphorus $(P)$ and Potassium $(K)$ of Mirzapur tehsils

\begin{tabular}{|c|c|c|c|c|c|c|c|c|c|c|c|c|}
\hline \multirow{2}{*}{ Tehsils } & \multicolumn{4}{|c|}{$\mathbf{N}$} & \multicolumn{5}{|c|}{$\mathbf{P}$} & \multicolumn{3}{|c|}{$\mathbf{K}$} \\
\hline & Mean & SD & $\gamma_{1}$ & $\gamma_{2}$ & Mean & SD & $\gamma_{1}$ & $\gamma_{2}$ & Mean & SD & $\gamma_{1}$ & $\gamma_{2}$ \\
\hline Chunar & 125.95 & 33.55 & -0.18 & -0.59 & 33.57 & 23.25 & 0.99 & 0.07 & 248.36 & 158.34 & 1.06 & 0.19 \\
\hline Mirzapur & 119.03 & 83.13 & 0.22 & -0.14 & 30.13 & 22.72 & 1.24 & 0.56 & 219.92 & 142.41 & 1.38 & 1.66 \\
\hline Marhihan & 142.47 & 27.52 & 0.57 & 0.46 & 26.32 & 18.94 & 1.45 & 1.94 & 273.86 & 144.72 & 0.67 & -0.22 \\
\hline Lalganj & 130.83 & 28.38 & 1.21 & 4.42 & 24.08 & 19.37 & 1.74 & 2.94 & 285.01 & 146.45 & 0.72 & -0.17 \\
\hline
\end{tabular}

\section{Micronutrients}

Results pertaining to Sulphur, Zinc, Copper, Manganese, Iron and Boron content of soils of all the tehsils of Mirzapur district were presented in Table 3.4a and Table 3.4b.

It is evident from Table 3.4a that the highest average (14.27) Sulphur belongs to the soil of Chunar tehsil as compared to lowest average (6.81) in Lalganj tehsil. Similarly, the highest average Iron (56.18) and average Copper (1.79) are found in Marhihan and Chunar tehsils as compared to lowest average $(21.62,1.01)$ in Mirzapur and Lalganj tehsils respectively.
The Standard deviation of Sulphur as measured is found to be highest (10.28) in Chunar tehsil as compared to lowest (6.56) in Lalganj tehsil. Standard Deviation of Iron was found to be highest (46.55) in Chunar tehsil as compared to lowest (24.26) in Mirzapur tehsil. Whereas, highest (0.96) Standard deviation of Copper was observed in Chunar tehsil as compared to lowest (0.72) in Mirzapur tehsil.

The distribution of Sulphur, Iron and Copper were found to be positively skewed in all the four tehsils and leptokurtic in all tehsils except Marhihan where the distribution of Copper is platykurtic.

Table 3.4a: Descriptive statistics of soil nutrients Sulphur (S), Iron (Fe) and Copper (Cu) of Mirzapur tehsils

\begin{tabular}{|c|c|c|c|c|c|c|c|c|c|c|c|c|}
\hline \multirow{2}{*}{ Tehsils } & \multicolumn{4}{|c|}{$\mathbf{S}$} & \multicolumn{4}{|c|}{$\mathbf{F e}$} & \multicolumn{4}{|c|}{$\mathbf{C u}$} \\
\hline & Mean & SD & $\gamma_{1}$ & $\gamma_{2}$ & Mean & SD & $\gamma_{1}$ & $\gamma_{2}$ & Mean & SD & $\gamma_{1}$ & $\gamma_{2}$ \\
\hline Chunar & 14.27 & 10.28 & 1.88 & 3.75 & 40.24 & 46.55 & 1.09 & -0.06 & 1.79 & 0.96 & 2.98 & 14.38 \\
\hline Mirzapur & 7.46 & 7.22 & 3.53 & 15.12 & 21.62 & 24.26 & 2.45 & 6.78 & 1.39 & 0.72 & 0.55 & 2.86 \\
\hline Marhihan & 10.39 & 8.95 & 1.75 & 3.22 & 56.18 & 38.17 & 0.88 & 0.24 & 1.54 & 0.94 & 0.42 & -0.73 \\
\hline Lalganj & 6.81 & 6.56 & 2.07 & 4.97 & 46.53 & 44.17 & 0.85 & -0.55 & 1.01 & 0.91 & 1.25 & 1.15 \\
\hline
\end{tabular}

The results presented in Table $3.4 \mathrm{~b}$ reveal the highest average (16.47) Maganese in Lalganj tehsil as compared to lowest average (7.22) in Mirzapur tehsil. Highest average (1.75) Zinc is found in Mirzapur as compared to lowest average (0.68) in Lalganj tehsil. The Standard deviation of Maganese is found to be highest (14.89) in Lalganj tehsil as compared to lowest (5.09) in Mirzapur tehsil. Similarly highest (1.11) Standard deviation of Zinc is found in Marhihan tehsil as compared to lowest (0.54) in Lalganj tehsil. Highest average (0.55) Boron is found in Chunar tehsil whereas lowest average (0.34) in
Marhihan tehsil. The Standard deviation of Boron is found to be highest (0.31) in Chunar tehsil and lowest (0.24) in Lalganj tehsil.

The distribution of Maganese, Zinc and Boron is found to be positively skewed in all the tehsils of Mirzapur district. The distribution of Maganese and Boron is leptokurtic for all tehsils whereas the distribution of Zinc is leptokurtic in Chunar, Marhihan and Lalganj tehsils and platykurtic in Mirzapur tehsil. 
Table 3.4b: Descriptive statistics of soil nutrients Maganese (Mn), Zinc (Zn) and Boron (B) of Mirzapur tehsils

\begin{tabular}{|c|c|c|c|c|c|c|c|c|c|c|c|c|}
\hline \multirow{2}{*}{ Tehsils } & \multicolumn{4}{|c|}{ Mn } & \multicolumn{4}{|c|}{ Zn } & \multicolumn{4}{|c|}{ B } \\
\hline & Mean & SD & $\gamma_{1}$ & $\gamma_{2}$ & Mean & SD & $\gamma_{1}$ & $\gamma_{2}$ & Mean & SD & $\gamma_{1}$ & $\gamma_{2}$ \\
\hline Chunar & 10.71 & 10.50 & 1.79 & 3.86 & 1.23 & 0.84 & 2.39 & 15.65 & 0.55 & 0.31 & 1.82 & 4.99 \\
\hline Mirzapur & 7.22 & 5.09 & 2.42 & 11.13 & 1.75 & 0.97 & 0.36 & -0.78 & 0.51 & 0.27 & 1.18 & 2.37 \\
\hline Marhihan & 7.23 & 10.50 & 1.68 & 3.28 & 1.71 & 1.11 & 0.25 & 0.25 & 0.34 & 0.28 & 4.26 & 26.20 \\
\hline Lalganj & 16.47 & 14.89 & 1.42 & 2.09 & 0.68 & 0.54 & 3.08 & 14.62 & 0.45 & 0.24 & 1.42 & 2.96 \\
\hline
\end{tabular}

\section{Conclusions}

Best fitted distributions of all soil characteristics are obtained using Easy Fit 5.6 Professional Software. Goodness of fit of the best fitted distributions is tested by Chi-Square test. $\mathrm{pH}$, EC, OC and Boron are found to follow Dagum distribution whereas Potassium and Iron are found to follow Fatigue Life distribution. Moreover EC, Nitrogen, Phosphorus, Sulphur, Maganese and Zinc are found to follow General Extreme Value, Error, Pearson 5, Pearson 5 (3P), Pearson 6 and Inverse Gaussian (3P) distributions respectively. Descriptive measures (Mean, Standard deviation, Skewness and Kutosis) are also calculated to know the soil status of different tehsils of Mirzapur district.

\section{References}

1. Athokpam H, Wani SH, Kamei D, Athokpam HS, Nongmaithem J, Kumar D et al. Soil macro-and micronutrient status of Senapati district, Manipur (India). African Journal of Agricultural Research. 2013; 8(39):4932-4936.

2. Begum K, Jahan I, Rahman MH, Chowdhury MS, Elahi SF. Status of some micronutrients in different soils of Gazipur district as related to soil properties and land type. Bangladesh Journal of Scientific and Industrial Research. 2009; 44(4):425-430.

3. Kumar M, Babel AL. Available micronutrient status and their relationship with soil properties of Jhunjhunu Tehsil, District Jhunjhunu, Rajasthan, India. Journal of Agricultural Science. 2011; 3(2)97p.

4. Nayak DC, Mukhopadhyay S, Sarkar D. Distribution of some available micronutrients in alluvial soils of Arunachal Pradesh in relation to soil characteristics. Journal of the Indian Society of Soil Science. 2000; 48(3):612-614.

5. Nazif W, Perveen S, Saleem I. Status of micronutrients in soils of district Bhimber (Azad Kashmir). Journal of Agricultural and Biological Science. 2006; 1(2):35-40.

6. Upadhyaya RC, Singh CS, Munna R. Micronutrient cation status of mandarin (Citrus reticulata Blanco) orchards of Sikkim. Journal of the Indian Society of Soil Science. 2000; 48(2):246-249.

7. Vijayakumar R, Arokiaraj A, Martin Deva Prasath P. Macronutrient and micronutrients status in relation to soil characteristics in South-East coast plain-riverine Soils of India. Oriental Journal of Chemistry. 2011; 27(2):567p.

8. Yadav BK. Micronutrient status of soils under legume crops in arid region of western Rajasthan, India. Academic Journal of Plant Sciences. 2011; 4(3)9497.

9. Yadav RL, Meena MC. Available micronutrients status and their relationship with soil properties of Degana soil series of Rajasthan. Journal of the Indian Society of Soil Science. 2009; 57(1):90-92. 